\title{
COORDENAÇÃO CONSENSUAL DE PRÁXIS PEDAGÓGICAS ENTRE TUTORES E PROFESSORES
}

\author{
(CONSENSUAL COORDINATION OF PEDAGOGICAL PRACTICES BETWEEN TUTORS AND \\ TEACHERS)
}

\author{
Tanise Paula Novello \\ Débora Pereira Laurino \\ Universidade Federal do Rio Grande, FURG (Brasil)
}

\section{RESUMO}

Este artigo tem como objetivo discutir, no âmbito da Educação a Distância (EaD), o entendimento da atividade de tutoria, bem como a ressignificação do papel do professor nesse novo contexto educacional. Para tal fim, foram realizadas entrevistas com professores e tutores que atuaram em disciplinas de cursos na modalidade a distância. Tais entrevistas são analisadas com base na Análise Textual Discursiva, a qual possibilitou estabelecer um diálogo entre os sujeitos de pesquisa e os teóricos que subsidiaram o estudo. Destaca-se ainda que, pelas narrativas, fica evidente a necessidade de superação do trabalho individualizado, o reconhecimento da diferença como complementaridade e o desenvolvimento de ações de capacitação de professores e tutores que fomentem formas de realizar um trabalho em conjunto e que leve coordenação das práxis pedagógicas. Realizar pesquisas como esta, que discutem as práticas e as ações na educação a distância, permite suspender algumas certezas e superar limitações.

Palavras-chave: educação a distância, professor, tutor a distância.

\begin{abstract}
This research paper examines distance education (DE) and the conceptualizuation of mentoring activities. It focuses on the "resignification" (new meaning) of the teacher's role in the modern educational context. Interviews were carried out with teachers and tutors who teach subjects in the distance education modality. These interviews were then analyzed using "discursive textual analysis" as its premise. This is a technique that promotes dialogue between research subjects and academics (the latter of which help finance research). In addition, the paper highlights the need to look beyond "individual work" and the "recognition of differences as a form of complementariness". It focuses on the implementation of training programs for professors and tutors, namely those who promote new ways of doing collaborative work and that aid the management of a pedagogical praxis. Doing research on distance education practices and activities is thus a means of both affirming certain truths and also overcoming limitations.
\end{abstract}


Keywords: distance education, teachers, distance tutors.

\section{UM OLHAR SOBRE O CENÁRIO DA EDUCAÇÃO A DISTÂNCIA}

A reinvenção da Educação a Distância (EaD) mediada pelas tecnologias apresenta-se como alternativa capaz de proporcionar maior alcance social para uma educação inclusiva, ou seja, que atenda à necessidade de aumentar a oferta de acesso ao ensino superior e de possibilitar a formação continuada de profissionais em exercício. Assim, percebe-se que o crescimento acelerado dessa modalidade tem trazido questões específicas sobre o ensinar e o aprender no contexto digital como, por exemplo, outras formas de conceber as dimensões de tempo e espaço, outras formas de relacionamento e de exercício da profissão de professor, demandando práticas pedagógicas que contemplem e integrem as especificidades desse contexto.

Os últimos anos, no Brasil, evidenciam um crescente reconhecimento da importância da Educação a Distância como alternativa para a formação inicial e continuada de professores e outros profissionais. A própria Lei de Diretrizes e Bases da Educação (LDB) apoia a implementação da EaD, incentivando o fomento a inúmeros projetos para as Instituições de Ensino Superior (IES) e outros órgãos, como secretarias de educação.

Um relatório elaborado pelo CensoEAD.br sobre a expansão da modalidade a distância no Brasil até o ano de 2009 mostra que, em nível de graduação, houve um crescimento superior a 90\% de alunos em relação ao ano de 2008, superando as expectativas iniciais (Censo, 2010). Assim, a medida que aumenta o número de cursos ofertados nessa modalidade, amplia-se a necessidade de professores e tutores para suprir as demandas do ensino a distância.

A LDB (Lei 9.394/96) que regulamenta a EaD, e a institui enquanto modalidade válida e equivalente para todos os níveis de ensino, aponta alguns critérios para o funcionamento de cursos nessa modalidade, e uma das exigências feita é a capacitação de tutores e professores que atuarão nos cursos. Estes, por sua vez, têm diferentes desenhos pedagógicos e trazem, em seu escopo, funções distintas atribuídas aos tutores. Tal entendimento da função do tutor está diretamente vinculado à proposta pedagógica do curso. Sendo assim, o tutor é um dos profissionais que, juntamente com o professor, participa ativamente da prática pedagógica. Os órgãos que regularizam a EaD determinam que o papel do tutor deve ser desempenhado por um profissional qualificado (no mínimo, graduado) e comprometido com o trabalho da Instituição que oferta o curso (Brasil, 2007). 
Sendo assim, a maioria dos cursos ofertados na modalidade a distância, especialmente os de graduação, tem duas equipes de tutores: os que atuam no polo (tutor presencial) e os que atuam na instituição proponente (tutor a distância). Apesar de o trabalho ser articulado entre eles, as funções diferenciam-se em alguns aspectos, como, por exemplo, o fato de que o tutor presencial atua no polo, acompanhando os estudantes em todas as disciplinas do curso, ou seja, possui um olhar horizontal do percurso do estudante no curso; sua atribuição principal é o acolhimento aos acadêmicos e o auxílio na organização das atividades e dos estudos. Já o tutor a distância atua na Instituição juntamente com o professor e sua atribuição principal é problematizar os conteúdos específicos da disciplina que atua e acompanhar a aprendizagem dos estudantes. Mas, embora existam diferenças nas funções dos tutores presencial e a distância, há também uma grande semelhança: a certeza da importância desse autor para a EaD, conforme se pode comprovar pelo diálogo de diferentes autores, como Gonzalez (2005), Litwin (2001) e Peters (2003).

Tanto no ensino presencial como no ensino a distância, a estrutura e as formas de atuação do professor dependem da Instituição, do alcance de sua área de atuação, das finalidades educacionais propostas e da natureza dos cursos oferecidos. Por isso, aqui, tem-se o interesse de discutir os diferentes aspectos que compõem a $\mathrm{EaD}$, pensá-los de forma integrada e articulada, superando os modelos educacionais hierarquizados e autoritários. Desse modo, tem-se como desafio propor um desenho de gestão educacional democrático, de modo a potencializar a construção de redes, com o objetivo de apoiar a construção do conhecimento e o desenvolvimento humano.

Nesse sentido, o presente artigo se constitui em um recorte do amplo sistema que compõe a EaD, focando o estudo na análise dos processos interativos entre professores e tutores a distância para a articulação das ações pedagógicas desenvolvidas no decorrer das disciplinas.

\section{FENÔMENO INVESTIGADO}

Com a intenção de compreender como professores e tutores estão se articulando na atuação conjunta nas disciplinas ministradas na modalidade a distância, o que implica na ressignificação do papel do professor e do tutor, foram elaborados dois roteiros de entrevista: um destinado a professores e outro para tutores.

O roteiro que subsidiou as entrevistas com os professores foi organizado em quatro eixos temáticos: 
- Perfil: questões que buscam identificar a formação do professor, o domínio da tecnologia e as experiências vivenciadas em cursos na modalidade a distância.

- Organização da disciplina: eixo que busca elucidar como as ações realizadas por uma equipe multidisciplinar, atuante na formação de professores e tutores e no atendimento permanente, podem auxiliar na elaboração do material, no processo de organização da disciplina, no planejamento dos encontros presenciais e na definição do processo de avaliação.

- Articulação com tutores: questões que buscam evidenciar as estratégias pedagógicas utilizadas no processo de articulação pelo grupo de professores e tutores a distância; e entendimento do papel do professor e do tutor no contexto da disciplina.

- Avaliação do processo: este grupo de questões possibilita fazer o resgate do trabalho realizado, apontando os limites, as possibilidades e dificuldades, evidenciando as alterações que seriam implementadas pelos professores, em caso de reoferta da disciplina.

As questões elaboradas para entrevistar os tutores a distância também foram organizadas em quatro eixos:

- Perfil: questões que buscam identificar a formação do tutor a distância, o domínio da tecnologia, as experiências vivenciadas em cursos na modalidade a distância e os fatores que o motivaram a atuar como tutor.

- Atuação na disciplina: esse conjunto de perguntas visa identificar as estratégias pedagógicas no processo de articulação utilizadas pelo grupo de professores e tutores a distância, bem como o entendimento do papel do tutor e do professor no contexto da disciplina.

- Articulação pedagógica: busca perceber a relação do tutor com o professor e com os demais tutores que atuaram na disciplina, bem como sua atuação na organização das aulas.

- Avaliação do processo: esse grupo de questões busca elucidar as dificuldades encontradas e a importância da participação dos tutores a distância nos cursos ofertados nessa modalidade de ensino.

Ambos os roteiros de entrevistas tiveram as questões organizadas em quatro eixos, contudo tais eixos estão interligados e, consequentemente, as questões 
perpassam mais de um eixo. Essa análise foi feita com base em quatro entrevistas (duas professoras e dois tutores a distância) que serão identificadas por letras aleatórias, num diálogo com autores da contemporaneidade que discutem o papel do tutor no contexto da educação a distância e as especificidades dessa modalidade.

Na apreciação das entrevistas, utilizou-se o método de Análise Textual Discursiva, na perspectiva apresentada por Moraes e Galiazzi (2007). Esse método se propõe a fazer uma leitura rigorosa e aprofundada de materiais textuais, com o objetivo de descrevê-los e de interpretá-los, no intuito de atingir uma melhor compreensão dos fenômenos e dos discursos a partir dos quais foram produzidos.

A análise textual discursiva pode ser entendida como um processo autoorganizado, composto por um ciclo de três elementos: a unitarização, que consiste da desmontagem do texto; a categorização, em que são construídas as relações entre os elementos unitários, combinando-os e classificando-os; e a construção de um metatexto, contendo a compreensão construída a partir de uma nova combinação dos ciclos anteriores.

\section{AÇÃo CONJUNTA UMA RECORRÊNCIA DA PRÁTICA PEDAGÓGICA}

Ao se percorrer a trajetória da educação, encontra-se presente, desde o século $\mathrm{XV}$, a figura do tutor (do latim, protetor), na Universidade, o qual tinha seu papel vinculado à orientação de estudantes no que concerne ao caráter religioso, com o objetivo de infundir a fé e a conduta moral. Já no século XX, o tutor assume o papel de orientador e acompanhante dos trabalhos acadêmicos, e é com esse mesmo sentido que se incorporou aos atuais programas de Educação a Distância.

Tanto a atuação como a compreensão dos papeis em um curso ou disciplina a distância dependem de fatores como: o entendimento sobre as funções do professor e do tutor, a disponibilidade para o trabalho coletivo e para a coordenação das ações e as práxis pedagógicas.

Porém essa compreensão para um trabalho cooperativo e coordenado ainda não se configura em nossa realidade como é possível observar que os tutores atribuem ao professor a responsabilidade pelos conceitos, uma vez que compreende ser o material didático produzido que contém a "exposição" de conteúdos, a definição de conceitos e a proposição de atividades. 
E o trabalho do professor é aquele que prepara o material, expõe a aula e deu. (Tutor R).

Eu não gosto do nome tutor, eu gosto de professor, eu posso ser um professor que não prepara o material, eu entendo que tenha uma questão de hierarquia (...). (Tutor $P$ )

Os relatos dos Tutores $\mathrm{R}$ e $\mathrm{P}$ evidenciam que tais tutores entendem a produção de material didático como de exclusiva responsabilidade do professor, não se sentindo parte desse processo. Por outro lado, Maggio (2001) destaca a importância da participação do tutor nessa produção, pois, segundo a autora, cabe ao tutor aprofundar os diferentes níveis de compreensão que envolvem as relações conceituais, a partir dos saberes prévios, usando estratégias pedagógicas adequadas, identificando erros frequentes, enriquecendo a proposta e atribuindo-lhe valor em função de sua intervenção. Nesse sentido, a participação do tutor, na concepção pedagógica do material didático utilizado durante a disciplina, é importante, uma vez que permite, ao longo do processo, identificar suas limitações e possibilidades, conforme a Professora I salienta:

Eu acho que é importante o tutor contribuir ao longo da elaboração do material, porque se tu chega no material que está pronto, se tu quiser mudar é meio complicado porque é muito em cima da hora (Professora I)

Acredita-se, realmente, que não caiba mais a concepção de professor enquanto aquele que conhece o conteúdo e "professa" sobre tal e o tutor, por sua vez, ser aquele que somente interage com o material produzido e com o estudante, sem uma crítica e um posicionamento pedagógico para tal. Por outro lado, cabe destacar também que tão pouco se quer um trabalho hierárquico, tal como aponta o Tutor P, mas o esperado é que considerem as diferenças de atividades como complementares e coordenadas nessa modalidade de ensino. Sob tal perspectiva, professor e tutor são responsáveis pela produção de material, mediação e orientação dos estudantes.

Assim, tratar o diferente como diferente implica no respeito a essa diferença e na compreensão da complementaridade dessas. A Professora I, por exemplo, aponta a necessidade de o tutor contribuir de alguma forma no material produzido pelo professor, considerando que os tutores a distância têm formação específica na 
área que atuam, sendo assim, certamente, essa parceria na produção seria viável e fortaleceria o vínculo entre esses autores.

Maggio (2001) destaca que os materiais didáticos se convertem em portadores da proposta pedagógica ao conter pressupostos acerca do conhecimento, do ensino e da aprendizagem no âmbito de concepções ideológicas e políticas. O material didático, então, exprime uma concepção de educação, por meio da sua estrutura, da organização didática dos conteúdos, assim, ao julgar o que considera mais importante, o professor contempla no material didático suas escolhas. (Possari, Neder, 2009). Tal afirmação corrobora com a necessidade de um trabalho coletivo entre professores e tutores e com a compreensão e o respeito das atividades de ambos.

Nas falas a seguir os tutores P e R demonstram entender sua tarefa inserida na ação docente, responsabilizando-se pela mediação pedagógica, e o tutor P salienta isso apesar de não estar inserido na construção e decisão do material didático.

Eu trabalho como se eu fosse o professor, eu não trabalho material, quando eu entro para trabalhar com meus alunos, eu chamo eles para trabalharem. Eu trabalho com eles da mesma forma que eu trabalho dentro da sala de aula, a única coisa é que eu não estou ali na frente do quadro. (Tutor P)

Eu acho que é o pilar, a base o alicerce. Eo principal deste tutor a distância é o relacionamento, com o aluno principalmente. Eu vejo que o trabalho do tutor é como um professor de ensino fundamental, aquele que está ali explicando, mostrando, mais em cima. (Tutor $R$ )

Pode-se pensar, então, a ação do professor e do tutor como complementares e de igual importância, ao se acreditar na aprendizagem como um processo que acontece no diálogo, na troca e na interação entre os diferentes autores da educação.

Apesar das atribuições distintas, o mais relevante, nesse contexto, são as relações humanas estabelecidas a partir da convivência entre esses autores. A convivência de pessoas "requer o estabelecimento de uma regulamentação que opera definindo o espaço de convivência como um domínio emocional declarativo que especifica os desejos de convivência, e, assim, o espaço de ações que o realizam" (Maturana, 2001, p. 74). 
A constância e a recorrência no conversar, que se constitui no entrelaçar do emocionar e do linguajar (Maturana, 2001) entre professores e tutores, poderá contribuir na interpretação e compreensão do material didático pelos estudantes, assim como nas intervenções didáticas ao longo da disciplina.

Para Rumble (2003), os tutores deverão estar familiarizados com o curso, com as práticas pedagógicas e as normas de avaliação, assim como com os conteúdos e a metodologia abordada. Estreitar as ações entre as diferentes práxis pedagógicas de professores e tutores, através de cursos de formação e reuniões periódicas, possibilitará a coordenação de ações, o que leva à coordenação consensual e contribui para que se desenvolva uma atmosfera de respeito mútuo e cooperação, em que professores e tutores sintam-se membros partícipes nesse processo de ensino e aprendizagem.

Torna-se possível, ainda, perceber, pelo relato do Tutor R, a relação que ele estabelece com estudantes, quando compara sua ação com a de professora de ensino fundamental. Esse tutor agrega a afetividade e o acompanhamento da aprendizagem como tarefa apenas do professor desse nível de ensino, desconsiderando que o professor de ensino médio e superior também tenha que se preocupar e se responsabilizar pela aprendizagem de seu aluno. Dessa forma, ele também problematiza a metodologia de ensino como reflexo da própria formação acadêmica, pois é difícil nos desvincularmos de nossos referenciais e de nossas vivências.

Manter com os alunos uma relação de cordialidade, afetividade e de respeito, assim como, sempre que possível, levantar questões que os levem a refletir, auxiliará o processo de aprendizagem, levando o aluno a pensar e analisar cada situação. A partir dos seus valores, conhecimentos, suas capacidades e atitudes, o tutor influencia no processo de formação dos seus respectivos alunos na direção da construção da autonomia, criando possibilidades de construção do conhecimento (Emerenciano, Sousa, Freitas, 2001).

Apesar de se entenderem como professor na atuação da tutoria, esses tutores ainda não percebem o trabalho coletivo e coordenado, tanto entre professor e tutor, quanto em relação às atividades afetivas e de trabalho, como se essas fossem antagônicas.

Ele tem que resgatar esses alunos, ele tem que propiciar que eles criem uma metodologia própria de aprendizagem (...). Trabalhar a parte das relações 
afetivas, das relações humanas, mostrar esse lado do trabalhador, o outro lado da vida. Eu acho que muito tutor entra para ser professor, e acaba tornando ruim para o grupo. (Tutor $P$ )

A gente correu mais atrás do tutor, que o tutor atrás da gente, e eu acho que deveria ser ao contrário, o tutor deveria ta analisando o nosso material, dizendo "olha isso ta bom". A gente pensou, eles iriam ler e entender, se eles não entendessem, a gente iria ver a nossa falha, e isso não ocorreu. Outra coisa que eu imaginei é que eles fossem corrigir atentamente os trabalhos, um ou outro corrigiu, os outros tu vê falhas, trabalhos que são iguais no mesmo grupo, tu tem que estar revisando, eu achei que isso era papel do tutor corrigir, isso não aconteceu. (Professora E)

Tanto no relato do Tutor P como no da Professora E, evidencia-se a dificuldade da compreensão da importância do trabalho do outro e do estabelecimento de uma relação heterárquica. Mas, sabe-se que considerar e conviver com a diferença é um exercício necessário, tendo em vista que se vive no mundo da complexidade, em que a multiplicidade dos saberes e das relações possíveis precisam ser operadas.

Nas narrativas dos professores e dos tutores, ficam claras as atribuições, a crítica e avaliação do trabalho do outro e pouco se percebe da autocrítica e da autorreflexão.

Eu gostava que eles resolvessem a atividade, para ver se o tutor ta sabendo a coisa, pode acontecer de eventualmente dar uma atrapalhação, a dificuldade da distância, do recurso que se usa para escrever matemática no computador, imagina se a pessoa ainda escreve ainda coisas erradas. (Professora I)

Para superar o trabalho individualizado ou "partido", precisa-se exercitar a construção coletiva na busca por planejamento e decisões conjuntas, por acerto de critérios e por práticas cooperativas. A figura do professor individual tende a ser substituída pelo professor coletivo. O trabalho coletivo promove a vivência de relações democráticas, convivência com a diferença, superação de preconceitos e consciência da importância de cada um para o coletivo. 
Professores e tutores precisam se sentir parceiros nesse espaço de convivência em cursos a distância. Uma atitude dinâmica no processo de ensino-aprendizagem implica no acompanhamento constante aos estudantes, o que gera um sentimento de pertencimento de "estar junto", o que os mantêm motivados. Essa aproximação possibilita que o estudante esclareça suas dúvidas e comunique seus problemas ou dificuldades.

Ao impingir a importância de um ambiente de respeito mútuo, propício para a construção de conhecimento gerado pelo bom relacionamento entre professor e tutores, esse ambiente estender-se-á aos estudantes. O que aprendemos e como aprendemos depende do espaço e das relações estabelecidas. Nesse sentido, Maturana (1993) considera fundamental uma educação que deseja conhecer e aceitar o outro como legítimo outro na sua existência, sem submissão, sem competição, respeitar e estimar as diferenças, valorizando a bagagem cultural do estudante, no respeito pelo outro.

Somos seres em relação, somos entre e com os outros e, na medida em que mais nos relacionamos, mais podemos significar nossas próprias práticas e relações. Um processo educativo que não enriquece a capacidade de se relacionar não é educativo (Gutierrez y Prieto, 1994). Propostas de trabalho que contemplam a interação e a formação em redes potencializam essa capacidade, assim como o desenvolvimento da criatividade, da autonomia e da cooperação.

\section{COMPREENSÕES POSSÍVEIS}

A figura do tutor, apesar de existir há muito tempo no contexto da EaD, é considerada relativamente recente, um vez que as políticas institucionais de inserção desse profissional no processo educacional ainda estão em desenvolvimento. Estudos e pesquisas de Gonzalez (2005), sobre avaliação de cursos em EaD, apontam que a qualidade do curso está diretamente vinculada ao desempenho desses profissionais que representam o elo entre os alunos-professores-instituição. O desafio é instituir políticas que regulamentem essa profissão, possibilitando a formação de equipes de tutores capacitados, de forma continuada e em serviço. Atualmente, devido a essa falta de regulamentação, o tutor é rotativo e, por consequência, existe a dificuldade em se consolidar um grupo estável e coordenado em suas práxis.

Em função disso, é indispensável que as instituições desenvolvam programas de capacitação de seu corpo de tutores, contemplando, pelo menos, três dimensões: formação de domínio específico do conteúdo; utilização dos recursos digitais e 
orientação pedagógica do processo de ensino-aprendizagem na modalidade a distância (Belloni, 1999). Investir na capacitação e formação continuada de um sistema de tutoria é necessário ao estabelecimento de uma educação a distância que deseja a coordenação consensual da prática pedagógica de tutores e professores.

Em decorrência do que foi apontado pelos professores e tutores, percebe-se a necessidade de intensificação do diálogo e da articulação desses na promoção do aperfeiçoamento da ação pedagógica, a fim de repensar as disciplinas no que se refere à superação das fragilidades e da importância das ações de ambos no processo de formação do estudante.

Este estudo aponta para o desafio de estabelecer uma cultura que considere a parceria entre professores e tutores no desenvolvimento de um trabalho cooperativo na modalidade de ensino a distância. Faz-se preciso entender que o papel do tutor vai além da orientação do estudante na compreensão dos temas específicos em estudo e na organização das atividades acadêmicas, é papel do tutor, também, intervir na concepção pedagógica do material didático, bem como no estabelecimento de estratégias pedagógicas, por meio de um processo coletivo e estreito com o professor. Ao contribuir com a proposta pedagógica, pela qual foram concebidos os materiais didáticos, sua intervenção poderá melhorá-la e, dessa forma, o diálogo pedagógico entre professores e tutores pode ser estabelecido com base na cooperação.

O trabalho conjunto e coordenado entre professor e tutor permitirá que haja uma coerência entre a atuação do tutor e os objetivos da proposta vislumbrada em consonância com o projeto do curso. Aliás, percebe-se o tutor como um professor que possui uma atuação específica e indispensável para os cursos ofertados na modalidade a distância, uma das diferenciações existentes está no que concerne à responsabilidade do professor, e não do tutor, com a disciplina na Instituição. Porém, a responsabilidade com o processo de ensino-aprendizagem é de ambos. Talvez a Institucionalização da tutoria possa ser um caminho a ser pensado, uma vez que essa se tornaria uma atividade permanente e reconhecida no âmbito acadêmico.

Espera-se que esse estudo estruturado a partir das narrativas de professores e tutores, contribua para o repensar de ações de formação inicial e continuada de tutores e professores que compõem o corpo de profissionais que atuam em cursos na modalidade a distância. A‘interaprendizagem’ (Gutierrez y Pietro, 1994), é capaz de enriquecer o processo de ação-reflexão através do confronto de ideias e opiniões. A formação humana está ligada às relações, ainda que cada um na sua dimensão de autonomia precise ser autor de seu próprio processo e contribua, dessa forma, 
com um ambiente educacional pautado nas relações de cooperação e respeito à legitimidade do outro.

\section{REFERÊNCIAS BIBLIOGRÁFICAS}

Belloni, M. L. (1999). Educação a Distância. Campinas, SP: Associados.

Brasil. Ministério da educação - SEED. (2007). Referenciais de Qualidade para Cursos a Distância - 2007. Brasília.

CENSO EAD. BR. (2010). Organização Associação Brasileira de Educação a Distância. São Paulo: Pearson Education do Brasil.

Emerenciano, M. S. J.; Sousa, C. A. L.; Freitas, L. G. (2001). Ser Presença como Educador, Professor e Tutor, (online). Colabor@. [em línea] Disponível em: http://www.ricesu.com.br/ colabora/n1/artigos/n 1/ido2.pdf (consulta 2010, 30 de novembro)

González, M. (2005). Fundamentos da tutoria em Educação a Distância. São Paulo: Avercamp.

Gutierrez, F.; Pietro, D. (1994). A Mediação Pedagógica: Educação à Distância Alternativa. Campinas: Editora Papirus. Litwin, E. (2001). Das tradições a virtualidade. In: Litwin, E. (Org.). Educação a distância: temas para o debate de uma nova agenda educativa. Tradução
Fátima Murad. Porto Alegre: Artmed Editora.

Maggio, M. (2001). O tutor na educação a distância. In: Litwin, E. (Org.). Educação a distância: temas para o debate de uma nova agenda educativa. Tradução Fátima Murad. Porto Alegre: Artmed Editora.

Maturana, H. (1993). Uma Nova Concepção de Aprendizagem. Revista Dois Pontos. Belo Horizonte, v.2, n.15, (28-35).

Maturana, H. (2001). Emoções e linguagem na educação e na política. Tradução: José Fernando Campos Fortes. Belo Horizonte: Ed. UFMG.

Moraes, R.; Galiazzi, M. C. (2007). Análise textual discursiva. Ijuí: Unijuí.

Peters, O. (2003). A educação a distância em transição. São Leopoldo: Ed. da Unisinos.

Possari, L. H. V.; Neder, M. L. (2009). Material Didático para a EaD: Processo de Produção. Cuiabá: EdUFMT.

Rumble, G. (2003). A gestão dos sistemas de educação a distância. Brasília: Editora UnB: UNESCO.

\section{PERFIL ACADÉMICO Y PROFESIONAL DE LAS AUTORAS}

Tanise Paula Novello. Doutoranda em Educação Ambiental pela Universidade Federal do Rio Grande (FURG), Mestre em Educação Ambiental pela FURG (2006), Graduada em Licenciatura em Matemática (1995). Atualmente, é professora assistente da FURG, vinculada ao Instituto de Matemática, Estatística e Física (IMEF), membro de grupo de Pesquisa Educação a Distância e Tecnologias e atua na Secretaria de Educação a Distância na formação inicial e continuada para docentes vinculados à educação a distância.

E-mail: tanisenovello@furg.br 
Débora Pereira Laurino. Doutora em Informática na Educação pela Universidade Federal do Rio Grande do Sul - UFRGS (2001), Mestre em Ciências da Computação (1995) pela UFRGS, Graduada em Licenciatura em Matemática (1990). Atualmente, é professora associada da FURG, vinculada ao Instituto de Matemática, Estatística e Física (IMEF), líder do grupo de Pesquisa Educação a Distância e Tecnologias, e Secretária Geral da Secretaria de Educação a Distância da FURG.

E-mail: deboralaurino@furg.br

DIRECCIÓN DE LAS AUTORAS:

Universidade Federal do Rio Grande - FURG

Secretaria de Educação a Distância

Av. Itália Km 8

96.201-900 - Rio Grande, RS - Brasil

Fecha de recepción del artículo: 06/04/11

Fecha de aceptación del artículo: 15/09/11

\section{Como citar este artículo:}

Novello, T. P.; Débora Pereira Laurino, D. (2012). Coordenação consensual de práxis pedagógicas entre tutores e professores. RIED. Revista Iberoamericana de Educación a Distancia, volumen 15, nº 1, pp. 179-191. 